\title{
Overview of Multi-functional Grid-connected Inverter and Its Application in Micro-grid
}

\author{
Tieyan Zhang, Xuefeng Yang and Yan Zhao \\ Shenyang Institute of Engineering, Shenyang, China. \\ Email: zty@sie.edu.cn
}

\begin{abstract}
Firstly, the paper describes the basic principles of the traditional grid-connected inverter. Then the paper proposes the multi-functional grid-connected inverter, and by comparing these four aspects: DC voltage conversion, inverter circuit, filter networks and power devices show the difference between multi-functional grid-connected inverter and traditional grid-connected inverter. Finally, considering the need of micro-grid, the paper makes a review on multi-functional inverter's applications in micro-grid from the function viewpoint. At the end of this paper, some possible future research directions about multi-functional grid-connected inverter are analyzed and discussed.
\end{abstract}

Keywords: distributed generation, power quality micro-grid, multi-functional grid-connected inverter.

\section{Introduction}

With the continuous consumption of fossil energy, resulting in the energy crisis and environmental pollution problems growing, 'green' and 'low carbon' has become an urgent demand for the development of the power system [1]. So the new energy generation of represented by the wind and light has been increasingly favored by countries of the world, and distributed generation technologies have been developed and improved continuously [2-4]. Because the distributed generation system not only is an important link of renewable energy connected to the grid, but also improve the stability of the traditional power grid to a certain extent, in recent years it has been given more and more attention [5-6]. However, wind, solar and other renewable energy sources with the characteristic of intermittent and random are a kind of typical non-controllable source. How to make non-controllable renewable energy access to power grid preferably is a major research focus for a long time. In order to solve the problem, some scholars have proposed the concept of micro-grid [7]. Micro-grid as a local power supply system of integrating a variety of renewable energy, energy storage devices and loads has been extensively studied recently.

Various renewable energy or energy storage systems generally require the inverter as grid-connected interface in distributed generation system and micro-grid [8-9]. However, making heavy use of power electronic devices just as the interface will bring a great challenge for the power quality of the distribution grid. In order to reduce the cost of distributed generation systems and power quality management, operation and maintenance costs, unit volume and improve the cost-effective of grid-connected inverter, some scholars have proposed a concept of multi-functional grid-connected inverter.

The paper is in the context of micro-grid and makes a review on multi-functional inverter and its applications in micro-grid, which has great signification for alleviating enormous impact on the large number of distributed grid-connected unit to the power grid, improving the ability of distribution grid admission dispersed renewable energy, 
and ensuring micro-grid security, reliable, efficient, economical operation.

\section{Grid-connected Inverter}

\subsection{The Basic Principles of Grid-connected Inverter}

Inverter is a device of converting the direct current (DC) into alternating current (AC), which consists of an inverter bridge, control logic and filter circuit, and its core part is the pulse width modulation (PWM) integrated controller. Figure 1 show the distributed power grid-connected circuit diagram of containing grid-connected inverter [10]. Where DC is distributed power. The DC output of distributed power access to the DC input of grid-connected inverter, the DC / AC converter circuit convert DC into AC under the action of inverter, and then the $\mathrm{AC}$ access to the power grid through the inductor $\mathrm{L}$ and the grid switch $\mathrm{S}$.

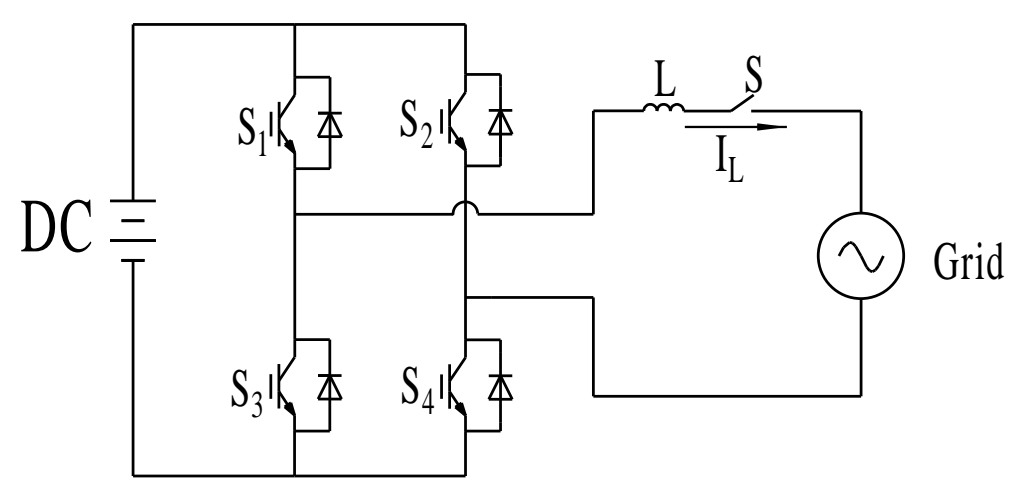

Figure 1. Distributed Power Grid-connected Circuit Diagram

\subsection{The System Model of Grid-connected Inverter}

The system control architecture is shown in Figure 2. Since the switch frequency $(20 \mathrm{kHz})$ is much higher than the power grid frequency and in order to conveniently analysis the impact of ignoring the switch operation on system, the PWM inverter unit is approximately seen as one link gain $\mathrm{K}$. In the Figure 2, G (s) is the transfer function of the system controller [11]; $\mathrm{R}$ is the inductance's equivalent series resistance; is the grid voltage; is the grid current reference signal which has the same frequency and phase as grid voltage.

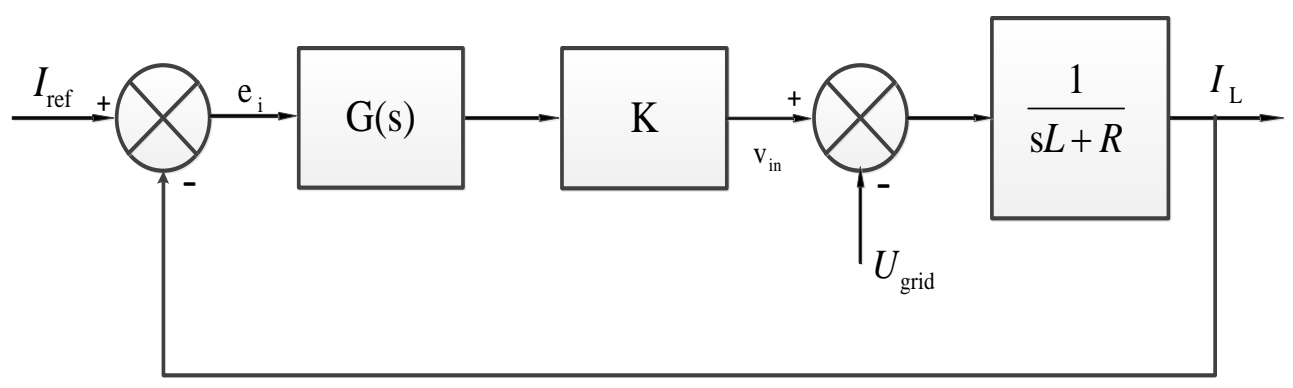

Figure 2. Model of Grid-connected Inverter System 
According to the system model we can get transfer function of grid-connected inverter output current [11]:

From the transfer function, we can know that grid-connected inverter output current is related to the reference current and grid voltage.

\section{Multi-functional Grid-connected Inverter}

The so-called multi-functional grid-connected inverter is a composite of many functions, such as: accomplishing the renewable energy or other micro power grid-connected, improving the power quality and so on [12]. The inverter equip with the same set of devices relative to multiple power electronic devices of functional separation, which can complete power quality adjustment and other additional features while grid-connected, thereby sharply reducing the investment and size of the system, particularly it is suitable for distribute power grid.

Multi-functional inverter system block diagram is shown in Figure 3. From the device composition, the advanced grid-connected inverter is different from the traditional grid-connected inverter in converting the DC voltage link, the inverter circuit, filter networks and power devices.

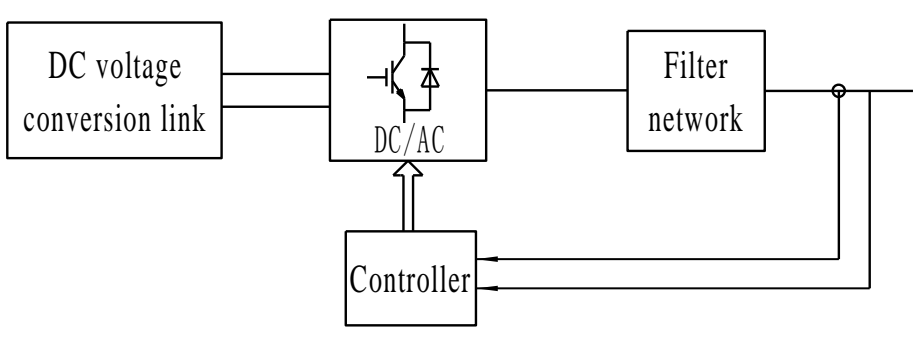

Figure 3. Multi-functional Inverter System Block Diagram

(1) From the point of view of DC voltage conversion

Three kind of DC voltage conversion link are shown in Figure 4. The DC voltage conversion link of traditional grid-connected inverter is mainly the boost transform circuit, which boost the DC output voltage of distributed power to meet the grid-connected conditions. However, since the lifting-voltage of boost convertion circuit is limited, the DC voltage range of distributed power grid which is receptible for grid-connected inverter is generally narrow. In recent years, the high-gain DC voltage conversion circuit with a variety of lifting-voltage has been widely studied [13]. 

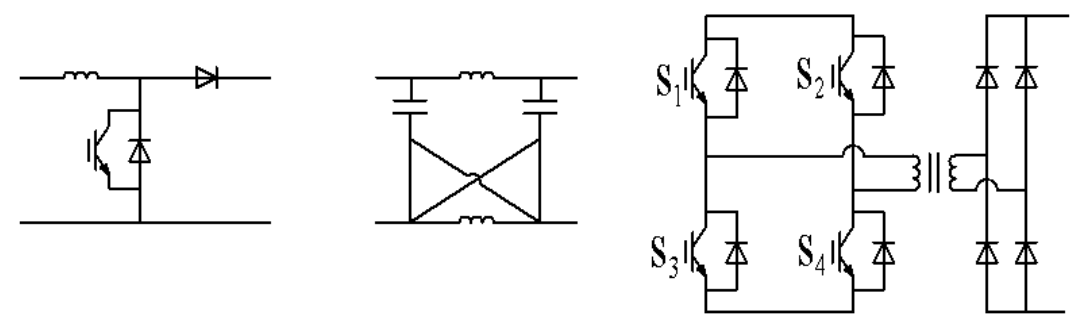

Figure 4. Three Kind of DC Voltage Conversion Link

Meanwhile, in order to eliminate that the potential leakage current of photovoltaic panels is harmful to personal safety [14], a number of DC voltage conversion link with high-frequency chain isolation are also noticed gradually [15].

In addition, in order to improve the flexibility and reliability of DC / AC conversion link, some advanced grid-inverter change the traditional voltage source converter mode and use a current source, $\mathrm{Z}$ source or quasi-Z-source converter structure [16].

(2) From the point of view of converter topology links

In order to meet some special functions, current source and multi-level NPC (neutral point clamped, NPC) of converter topology also began to appear in small power grid-connected inverter. These topologies can improve the operating performance of grid-connected inverter [17-18]. It should be noted that with the advent of advanced IGBT module structures, such as multi-level RB-IGBT, the grid-connected inverter implementations become more flexible.

In order to suppress the potential common mode voltage or differential mode voltage in the PV grid-connected inverter, the programs of high-frequency isolation on the DC side or low frequency isolation on the AC side the paper mentioned earlier are used, but the transformer in the programs will increase size and cost of system. In recent years, some new converter topologies begin to appear and lay a solid foundation for the non-isolated grid-connected inverter development [19]. Meanwhile, in order to ensure that renewable energy ang local storage unit connect grid, literature [20] found that some converter topology switch can be reused, so a kind of new converter topology with nine switch tubes appear. And in order to achieve the multi-level mode of grid-connected converter, literature [21] presented a kind of converter topology with single-phase converter multi-level which is achieved by the use of six switch tubes.

(3) From the point of view of power electronic device material

With the development of wide band gap material devices, such as $\mathrm{SiC}$, power electronic devices with a smaller on-state resistance and higher switching speed will greatly improve the switching frequency and efficiency of grid-connected converter. The advanced grid-connected converter with small size, light weight and high efficiency will be provided a reliable protection [22-23].

From the point of view of power electronic device structure, the new Fuji Electric's RB-IGBT structure (or Simon Kang's T-NPC structure) can effectively reduce system losses, and improve the efficiency of three-level structure grid-connected inverter [24].

(4) The grid-connected inverter's DC / AC conversion circuit transform DC voltage or current into switching pulses. In order to eliminate the impact of switching frequency harmonic voltage and current component on power grid in that process, in gengral, there is a passive low-pass filter network between inverter circuitIt and power grid. Common kind of filter network main types are: L type, LC type, LCL type and LCLL type [25] and these are shown in figure 5. 


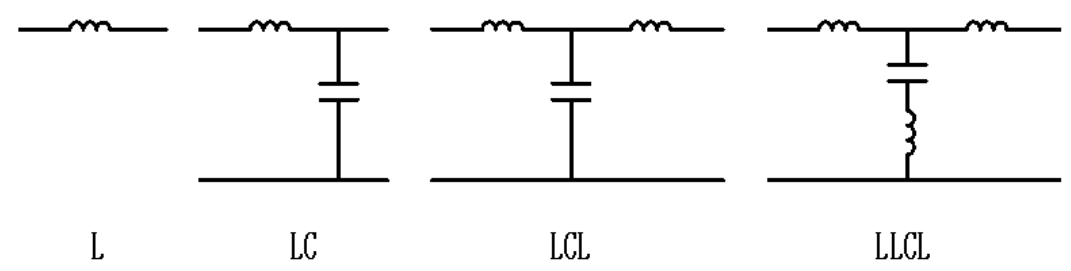

Figure 5. Common Kind of Filter Network Main Types

In general, the rate of high frequency attenuation of L-type filter is only $20 \mathrm{~dB} / \mathrm{dec}$. In order to obtain a good high frequency ripple current attenuation performance, the inductance values need to be enhanced and with the increase of the inductance values, the size and cost of the inductor will increase. So the LC and LCL type filter network structure was presented and their rate of high frequency attenuation is $40 \mathrm{~dB} / \mathrm{dec}$ and $60 \mathrm{~dB} / \mathrm{dec}$ [26]. It should be noted that LC type filter network and the equivalent power system impedance (primarily inductance) together form an LCL filter structure. Obviously, the higher the rate of high-frequency attenuation is, the stronger the inhibition ability is to the ripple current. However, because the LCL filter model which has three storage elements is a third-order dynamic response equation and there is a natural resonance point, grid-connected inverter stability and control will be brought great difficulty [27]. On the one hand, we can increase the passive damping resistance to damped harmonic component in the filter capacitor branch, but the efficiency of the system will be reduce due to existing resistance [28]. While some improved LCL filter passive damper method with resonance bypass can reduce the loss of damping resistor to some extent, the complexity of the system will be increased [29]. Therefore, the active damping program of basing on control has been widely studied [30]. On the other hand, we can enhance LCL filter grid-connected inverter control performance by the use of some special control strategies, such as: weighted current feedback control [31], multi-loop feedback control [32], the pole-zero configuration control [33], the optimization control of basing on state-space [34] and so on. In order to get the better filtering performance and reduce system size, literature [35] proposed the concept of LCL filter integrated magnetic. Moreover, in order to further improve the high frequency attenuation characteristics of system, recently there have been LLCL type filter grid-connected inverters [36].

\section{Application of Multi-functional Grid-connected Inverter in Microgrid}

With the grid-connected operation of the distributed generation system, grid-connected inverter has become the essential equipment in Microgrid. Due to the rapid development of power electronics technology, the multi-functional grid-connected inverter is more prominent, flexible and diversified. The application of multi-functional grid-connected inverter in Microgrid is mainly reflected in the following five aspects.

\subsection{Scheduling Aspects}

In the context of renewable energy dispersive access, State Grid requires that a single station access capacity of distributed power is not greater than $6 \mathrm{MW}$ and that distributed power can access $10 \mathrm{kV}$ and the following distribution network [37]. 
However, due to the large number of distributed grid-connected units in the distribution grid, the centralized communication scheduling of the distributed grid-connected units is very difficult. In order to solve this kind of problem, literature [38] proposed the concept of network control, but control network is still difficult to meet the unified management and scheduling of distributed generation and the burden of the central controller will increased dramatically. At the same time, the network control delay, packet loss and other issues make the reliability of network control reduce. Therefore, the best strategy is the distributed autonomous operation control strategy which is proposed by the literature [39] in the face of the problem of large scale decentralized grid connected units. The kind of control strategy is mainly based on grid-connected inverte to simulate the traditional generator. Since this kind of control method does not require distal or other grid-connected unit information, namely, making adjustment on the basis of the state of the power grid, the distributed grid-connected unit can participate in power grid regulation independently and autonomously.

\subsection{Improving the Power Quality}

The distributed grid-connected power generation system is often applied to the weak power grid terminals. The reactive power and harmonic wave have the most serious impact on the power quality in the weak power grid terminals, especially the three-phase voltage unbalance is the typical characteristic of the distribution network. In order to ensure that the grid-connected inverter continuously operate under unbalanced grid voltage, harmonics and other non ideal conditions, in recent years, the research on grid-connected inverter balanced or unbalanced voltage sag and voltage harmonics through research ability has been noticed widely [40-41]. Literature [42] just put forward the control strategy that within the distribution network is fitted with an active or passive filter.

In General, the passive filtering device structure is simple, low cost, high reliability, however, due to active power quality control devices more flexible and higher performance of operation, it has been increasing used in recent years. It is worth noting that, on the one hand, the grid-connected inverter has the same converter-topology with active power filter (APF), dynamic voltage regulator (DVR) and so on, that is the grid-connected inverters with the potential of control access point power quality. On the other hand, due to the wind, photovoltaic randomness, volatility and uncontrollable make that the wind turbine and photovoltaic cell output can't possibly be in full state, and comparing with the installed wind turbines or solar battery capacity, the installation capacity of grid-connected inverter exists in a certain margin. So the grid-connected inverter has the ability to tackle the power quality of access point. The concept of multi-functional grid-connected inverter of integrating renewable grid-connection and power quality management has been noticed widely [43]. A typical multi-functional grid-connected inverter block diagram is shown in Figure 5. Because this kind of grid-connected inverters have numerous functions, such as: without introducing additional power quality control devices, it can improve power quality of distribution network, the investment cost, volume and costs of operation and maintenance of the system will be decreased and the reliability of the system will be improved [44]. Literature [45] verified that multi-functional grid-connected inverter can compensate the reactive power, harmonic and unbalanced currents in the access point and provide necessary active and reactive power support to the distribution network [46], and apply to control the power quality and optimize the compensation in the micro-grid. Literature [47] studied the control strategy of sharing the harmonic and the reactive current among the multi-functional grid-connected inverters. 


\subsection{Power Grid Impedance Detection}

Power grid impedance has a greater impact on power quality of grid-connected current of the grid-connected inverter. The larger the system impedance is, the greater the influence is on the grid-connected inverter stability, the more serious the deterioration is in the power quality [48]. In addition, a large number of studies have shown that mismatch of the system impedance network may cause system of series-parallel resonant to lead grid-connected inverter to trip and endanger the power system stable operation after large-scale distributed renewable energy accessing to the distribution network through the grid-connected inverter [49]. Therefore, the system impedance has important significance for the distributed renewable energy grid-connected unit. Some grid-connected technical standards from the Europe and Germany clearly demanded that the grid-connected inverter should check the system impedance and can halt work or convert into the islands operation pattern when the impedance of the system change dramatically [50-51]. Thus it can be seen that the detection of the system impedance should also become an important part of the distributed grid-connected power generation unit.

Generally, the detection method of the system impedance can be divided into two categories: measurement method and estimation method. In the method of measurement, the impedance of the system is directly measured by the additional measuring device [52], and the method is simple and feasible, but additional hardware input will be introduced. Instead, the estimation rule directly uses the digital controller of the grid connected inverter to accomplish the detection of the system impedance, and this method is divided into active and passive [50].

\subsection{Impedance Remodeling}

Analysis shows that the impedance of the system has important effects on the operation of grid-connected inverters, and there are also some methods can effectively detect the impedance of the system size. However, in order to improve the system impedance, in particular, provide the system the necessary damping and curb the possible series-parallel resonance phenomenon risk need to reshape the system impedance [53]. That is that changing the characteristics of the grid-connected inverter makes grid-connected inverter show more the resistance and provide power grid with complex inductive and capacitive element more damping.

In General, grid-connected inverter and system lines present perceptual, but filter capacitor present capacitance. When the resistive component of the damping of the system is lacking, series-parallel resonance will be formed easily in between these inductors and capacitors. Through grid-connected inverter system with the necessary resistive components can be effectively suppressed a series-parallel resonant. This is the concept of impedance remodeling.

\subsection{The Island and Grid-connected Dual Mode Operation of Grid Connected Inverter}

In terms of the dual-mode operation of island and grid-connected of grid connected inverter, in order to improve the efficiency and flexibility of the distributed grid-connected renewable energy, a growing number of grid-connected inverters with island and grid-connected dual mode operation capability is required [54-55]. In the normal operation mode of the power grid, grid-connected inverter is in grid-connected operation state; when the failure occurs, islands of grid-connected inverters should be able to run to provide local critical loads with high quality power supply. This is the concept of dual mode operation of the grid-connected inverter. In order to guarantee the 
uninterrupted power supply to the local critical loads in the process of switching the operation mode, grid-connected inverter with seamless handover technology is very necessary between the different operation modes. Literature [56-58] studied that kind of problems.

\section{Analysis and Prospect}

Above all, the advanced multi-functional grid-connected inverter which is fit for connecting the power grid is in the foundation of traditional inverter basic framework and through modifying its system hardware and software, so that their structure is more optimized; function is more diverse and performance is improved. However, from the point of view of large-scale distributed renewable energy dispersion access, the hardware transformation may require more technical, economic investment and a longer development cycle. If by remoulding the traditional grid-connected inverter in the software makes it adapt and actively improve the distribution grid complex operating environment, the investment costs will be greatly reduced. Thus, it can not only reduce the impact of the grid connected inverter to the distribution network, but also improve the acceptance ability of the distribution network to the decentralized renewable power.

Based on the above analysis, it can be found that a perfect multi-functional grid-connected inverter can be equipped with powerful advanced control strategy in the foundation of traditional hardware circuit frame. These strategies include: advanced digital phase lock technique and parallel / off network operation mode seamless switching technology, including virtual synchronous generator technology, system impedance on-line identification and islanding protection technology, harmonic and reactive current compensation, low voltage / harmonic voltage across technologies, system impedance remodeling technique, a series of software control module, as shown in Figure 6 [59].

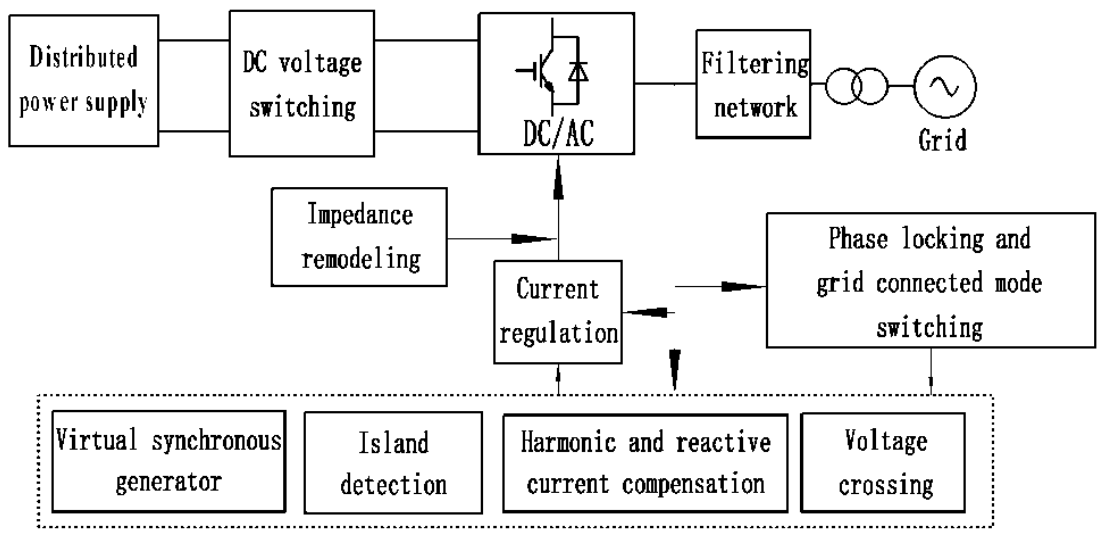

Figure 6. Frame of an Advanced Grid-tied Inverter

\section{Conclusion}

In recent years, with the further study on distributed generation and micro-grid technology, grid-connected inverter as one of the key components have also been paid close extensive attention. In order to enhance the cost-effective of grid-connected inverter and improve the power quality of distributed generation system, a new research field with the grid-connected inverter of complex function has been proposed. Based on the features of multiple functions, multi-functional grid-connected inverter has been widely used in the distributed generation system. For the multi-functional 
grid-connected inverter, the paper reviewes the multi-functional inverter and its application in the micro-grid from the point of view of hardware device and multi function and expounds that the function is applied in the five respects that is the system planning and scheduling, improve the power quality, system impedance detection and impedance remodeling, micro-grid dual-mode operation. Finally, the paper discusses simply some measures to multi-functional grid-connected inverter, such as how to reduce the impact of large-scale renewable energy distributed connecting the power grid on distribution network, how to improve the capacity of distribution network accepting the decentralized renewable energy, and also analyzes simply the advanced multi-functional grid-connected converter should be equiped the control function and control strategy. These will have a certain guiding significance to the development and research of the multi-functional grid-connected converter in the future.

\section{Acknowledgement}

This work was supported by This work is supported by National Nature Science Foundation of China under Grant 61304069, 61372195, 61371200, the Fundamental Research Fund of Liaoning Provincial Education Department Key Laboratory under Grant LZ2014050 and the Scientific Research Fund of Liaoning Provincial Education Department under Grant L2014526, L2014517). The authors also gratefully acknowledge the helpful comments and suggestions of the reviewers, which have improved the presentation.

\section{References}

[1] S. Rahman. Green power: What is it and Where can we find it? [J]. IEEE Power and Energy Magazine, 1, 1 (2003)

[2] R. C. Dugan, T. E. McDermott. Distributed Generation [J]. IEEE Industry Applications Magazine, 8, 2 (2002)

[3] Y. X. Yu, W. P. Luan. Smart Grid and Its Implementations [J]. Proceedings of the CSEE, 29, 34 (2009)

[4] S. Carley. Distributed Generation: an Empirical Aanalysis of Primary Motivators [J]. Energy Policy, 37,5 (2009)

[5] R. H. Iasserter. Microgrids and Distributed Generation [J]. Journal of Energy Engineering, 133, 3 (2007)

[6] C. S. Wang, S. X. Wang. Study on Some Key Problems Related to Distributed Generation Systems [J]. Automation of Electric Power Systems, 32, 20 (2008)

[7] B. Kroposki, R. H. Lasserter, T. Ise. Making Microgrids Work [J]. Power and Energy Magazine, 6, 3 (2008)

[8] F. Blaabjerg, Z. Chen, S. B. Kjaer. Power Electronics as Efficient Interface in Dispersed Power Generation Systems [J]. IEEE Transactions on Power Electronics, 19, 5 (2004)

[9] Y. S. Xue, L. C. Chang, S. B. Kjaer. Topologies of Single-phase Inverters for Small Distributed Power Generators: an Overview [J]. IEEE Transactions on Power Electronics, 19, (2004)

[10] X. Q. Guo, W. Y. Wu, Q. L. Zhao. Comparative Analysis and Digital Implementation of Novel Control Strategies for grid-connected inverters [J]. Nsactions of China Electrotechnical Society, 22, 5 (2007)

[11] Q. L. Zhao, X. Q. Guo, W. Y. Wu. Research on Control Stmtegy for Single-Phase Grid-connected Inverter [J] Proceedings of me CSEE, 27, 6 (2007)

[12] Z. Ceng, H. Yang, R. X. Zhao, H. Tang, L. Jin, M. L. Zhu, S. Q. Tang. Review of Multi-functional Grid-connected Inverter [J]. Electric Power Automation Equipment, 32.8 (2012)

[13] W. H. Li, X. N. He. Review of Nonisolated High-step-up DC/DC Converters in Photovoltaic Ggrid-connected Applications [J]. IEEE Transactions on Industrial Electronics, 58, 4 (2011)

[14] H. F. Xiao, S. J. Xie, W. M. Chen. Study on Leakage Current Model for Ttransformerless Photovoltaic Grid-connected Inverter [J]. Proceedings of the CSEE, 30, 18 (2010)

[15] Q. Wang, W. F. Hu, Y. Y. Bai. Novel High Frequency Isolated Grid-connected Inverter [J] . Low Voltage Apparatus, 4 (2012)

[16] J. Anderson, F. Z. Peng. A Class of Quasi-Z-source Inverters [C]. Proceedings of IEEE Industry Applications Society Annual Meeting. Alberta, Canada: IEEE, (2008)

[17] Calais M , Agelidis V G . Multilevel converters for single-phase grid connected photovoltaic systems-an overview [C]. Proceeding of IEEE International Symposium on Industrial Electronics. Pertoria, South Africa: IEEE, (1998) 
[18] C. H. Wu, G. C. Chen, H. Y. Ding. A Novel Control Strategy for Photovoltaic Grid-connected Inverter [J]. Proceedings of the CSEE, 27, 33 (2007)

[19] H. F. Xiao, C. Yang, S. J. Xie. NPC Three-level Grid-connected Inverter with Lleakage Current Suppression [J]. Proceedings of the CSEE, 30, 33 (2010)

[20] C. L. Poh, Z. Lei, G. Feng. Compact Integrated Energy Systems for Distributed Generation [J]. IEEE Transactions on Industrial Electronics, (2013)

[21] B. R. Lin, T. Y. Yang. Implementation of Active Power Filter with Asymmetrical Inverter Legs for Harmonic and Rreactive Power Compensation [J] . Electric Power Systems Research, 73, 2 (2005)

[22] S. B. Pan, X. F. Hao. Research of High Efficiency Solar Inverter Using SiC Devices [J]. Manufacturing Automation, 33, 8 (2011)

[23] K. Sheng, Q. Guo, J. M. Zhang. Development and Prospect of SiC Power Devices in Power Grid [J]. Proceedings of the CSEE, 32, 30 (2012)

[24] Y. Liu, J. H. Su. Efficiency Analysis of a New Three-level Grid-connected Photovoltaic Inverter Based on RB-IGBT [J]. High Voltage Apparatus, 48, 6 (2012)

[25] G. Q. Shen. Study on the Grid-connected Technology of Fuel Cell[D]. Hangzhou: Zhejiang University, (2008)

[26] Z. Ceng, R. X. Zhao, H. Yang. Reduction Model and Sliding Mode Variable Structure Control for Grid-connected Inverters with Isolation Transformer [J]. Automation of Electric Power Systems, 36, 3 (2012)

[27] M. Liserre, F. Blaabjerg, R. Teodorescu. Grid Impedance Estimation via Excitation of LCL-filter Resonance [J]. IEEE Transactions on Industry Applications, 43, 5 (2007)

[28] X. F. Pe, R. A-Alzola, M. Liserre. Analysis of the Passive Damping Losses in LCL-filter-based Grid Converters [J]. IEEE Transactions on Power Electronics, 28, 6 (2013)

[29] W. Q. Zhao, G. Z. Chen. Application of Improved LCL Filter Topology in Aactive Power Filter [J]. Mechanical \& Electrical Engineering Magazine, 25, 12 (2008)

[30] W. Gullvik, L. Norum, R. Nilsen. Active Damping of Resonance Oscillations in LCL-filters Based on Vvirtual Flux and Virtual Resistor [C]. Proceeding of IEEE European Conference on Power Electronics and Applications Aalborg, Denmark: IEEE, (2007)

[31] G. Shen, D. Xu, L. Cao. An Improved Control Sstrategy for Grid-connected Voltage Source Inverters with an LCL Ffilter [J]. IEEE Transactions on Power Electronics, 23, 4 (2008)

[32] S. Y. Yang, X. Zhang, C. W. Zhang. Strategy Design of Multiple Feedback Loop Control for Grid-connected Voltage Source Inverter with LCL Filter [J]. Automation of Electric Power Systems, 35,5 (2011)

[33] F. Liu, Y. Zhou, S. Duan. Parameter Design of a Two-current-loop Controller Used in a Grid-connected Inverter System with LCL Filter [J]. IEEE Transactions on Industrial Electronics, 56, 11 (2009)

[34] J. Dannehl, F. W. Fuchs, X. F. Th. PI State Space Current Control of Grid-connected PWM Converters with LCL Filters[J]. IEEE Transactions on Power Electronics, 25, 9 (2010)

[35] D. H. Pan, X. B. Ruan, X. H. Wang. Magnetic Integration of the LCL Filter in Grid-connected Iinverters [J]. Proceedings of the CSEE, 33, 6 (2013)

[36] W. Wu, Y. He, F. Blaabjerg. An LLCL Power Ffilter for Single-phase Grid-tied Inverter [J]. IEEE Transactions on Power Electronics, 27, 2 (2012)

[37] Y. Zou. State Grid Has Issued the Service Opinions for Ggrid-tied Distributed Energy Resources [N]. Newspaper of State Grid, 28, 1 (2013)

[38] L. Y. Zhang, J. H. Zhao, F. S. Wen, Y. S. Xue, J. Wang. Robust Networked Control of Eelectric Vehicles Bbased on Linear Matrix Inequalities [J]. Automation of Electric Power Systems, 37, 20 (2013)

[39] J. M. Guerrero, M. Chandorkar, T. Lee. Advanced Control Architectures for Intelligent Microgrids Part I: Decentralized and Hierarchical Control [J] . IEEE Transactions on Industrial Electronics, 60, 4 (2013)

[40] J. B. Hu, H. Nian, H. L. Xu. Dynamic Modeling and Improved Control of DFIG Under Distorted Grid Vvoltage Conditions [J]. IEEE Transactions on Energy Conversion, 26, 1 (2011)

[41] H. S. Wang, W. Zhang, J. B. Hu. A Control Strategy for Doubly-fed Induction Generator Wind Turbines Under Asymmetrical Grid Voltage Conditions Caused Byfaults [J]. Automation of Electric Power Systems, 34, 4 (2010)

[42] S. K. Khadem, M. Basu, M. F. Conlon. Power Quality in Grid Connected Renewable Energy Systems Role of Custom Power Devices [C] Proceeding of International Conference on Renewable Energy and Power Quality. Granada, Spain: ICREPQ, (2010)

[43] Z. Zeng, R. X. Zhao, H. Yang. Topologies and Control Strategies of Multi-functional Grid-connected Inverters for Power Quality Enhancement: A Comprehensive Review [J]. Renewable and Sustainable Energy Reviews, 24, (2013)

[44] Z. Zeng, H. Yang, R. X. Zhao. Overview of Multi-functional Grid-connected Inverters [J]. Electric Power Automation Equipment, 32, 8 (2012)

[45] Topology and Control of Multi-functional Grid-connected Inverter [J]. Electric Power Automation Equipment, 33, 1 (2013) 
[46] Z. Zeng, H. Yang, R. X. Zhao. Multi-functional Grid-connected Inverter and Its Application in Microgrid [J]. Automation of Electric Power Systems, 36, 4 (2012)

[47] Z. Zeng, H. Yang, C. Cheng. Harmonic and Reactive Currents Sharing by Multi-functional Grid-connected Inverters in a Micro-grid [C]. Proceeding of IEEE International Conference on Electrical Machines and Systems. Sapporo, Japan: IEEE, (2012)

[48] X. Chen, J. Sun. Characterization of Inverter-grid Interactions Using a Hardware in the Loop Systemtest-bed [C]. Proceeding of IEEE International Conference on Power Electronics and ECCE. Jeju, Korea: IEEE, (2011)

[49] J. H. R. Enslin, P. J. M. Heskes. Harmonic Interaction Between a Large Number of Distributed Power Inverters and the Distribution Network [J]. IEEE Transactions on Power Electronics, 19, 6 (2004)

[50] L. Asiminoaei, R. Teodorescu, F. Blaabjerg. A Digital Controlled PV-inverter with Grid Impedance Eestimation for ENS Detection [J]. IEEE Transactions on Power Electronics, 20, 6 (2005)

[51] S. Cobreces, E. J. Bueno, D. Pizarro. Grid Impedance Monitoring System for Distributed Power Generation Electronic Interfaces [J]. IEEE Transactions on Instrumentation and Measurement, 58, 9 (2009)

[52] Y. A. Familiant, H. Jing, K. A. Corzine. New Techniques for Measuring Impedance Characteristics of Three-phase AC Power Systems [J]. IEEE Transactions on Power Electronics, 24, 7 (2009)

[53] M. Cespedes, J. Sun. Impedance Shaping of Three-phase Grid-parallel Voltage-source Converters [C]. Proceeding of IEEE Applied Power Electronics Conference and Exposition. Orlando, FL, USA: IEEE, (2012)

[54] Z. Wang, L. Xiao, Z. L. Yao. Design and Implementation of a High Performance Utility-interactive Inverter [J]. Proceedings of the CSEE, 27, 1 (2007)

[55] L. Guo, A. G. Xu, S. J. Xie. Research on Indirect Current Control Algorithm for Grid-connected Inverter [J]. Power Electronics, 42, 4 (2008)

[56] X. H. Wang, C. J. Zhang. Study of Control Strategy for Seamless Transfer of Grid-connected Distributed Generation Systems [J]. Transactions of China Electrotechnical Society , 27, 2 (2012)

[57] J. K. Sheng, R. Zeng, H. Nian. Flexible Switching Technology of New Energy Distributed Generation System While Connecting and Disconnecting to the Grid [J]. High Power Converter Technology, 2 (2012)

[58] Z. Liu, J. J. Liu. A Control Method for 3-phase Inverters Enabling Smooth Transferring of the Operation Modes of Distributed Generation System [J]. Transactions of China Electrotechnical Society, 26, 5 (2011)

[59] Z. Zeng, R. X. Zhao, S. Q. Tang, H. Yang, Z. P. Lv. An Overview on Advanced Grid-connected Inverters Used for Decentralized Renewable Energy Resources [J]. Proceedings of the CSEE, 33, 24 (2013).

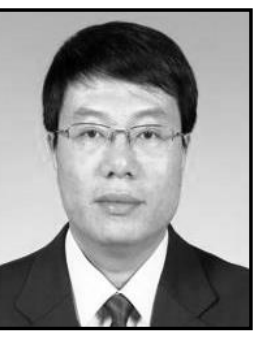

\section{Authors}

Tieyan Zhang, He was born in 1962 . He received the $\mathrm{Ph}$. D. degree in control theory and control engineering from Northeastern University, Shenyang, China, in 2007.

$\mathrm{He}$ is currently a professor of Shenyang University of Technology, Shenyang. His current research interests include fuzzy controls, fault diagnosis on electric power systems, and stability analysis on smart grids.

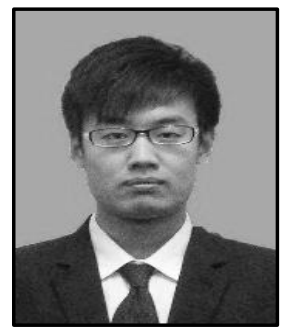

Xuefeng Yang, He received the B.E. degree in Electrical Engineering and Automation from Laoning institute of Science and Technology, Liaoning, China in 2014.

$\mathrm{He}$ is currently working towards the Master in Electric Engineering in Shenyang Institute of Engineering. 


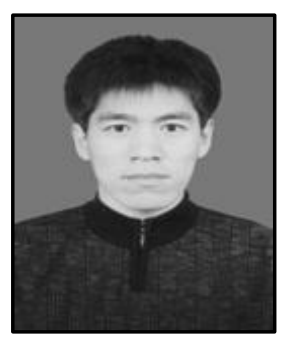

Yan Zhao, He received the Ph.D. degree in control engineering from Northeastern University, Shenyang, China, in 2008.

$\mathrm{He}$ is currently an associate professor with the School of Renewable Energy, Shenyang Institute of Engineering, Shenyang. His current research interests include fuzzy control theory and distributed generation technique. 